\title{
Possibility of use of the natural porcelain stone of a Djany-Djol field (Uchkurt) in orthopedic stomatology (after enrichment) Amiraev U. ${ }^{1}$, Dautova A. ${ }^{2}$, Zhekisheva S. $^{3}$ \\ Возможность использования природного фарфорового камня месторождения «Джаны-Джол» (Учкурт) в ортопедической стоматологии (после обогащения) Амираев У. А. ${ }^{1}$, Даутова А. И. ${ }^{2}$, Жекишева С. Ж. ${ }^{3}$
}

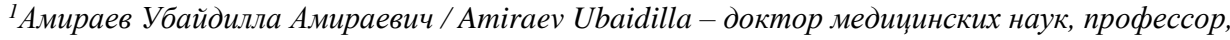 \\ кафедра ортопедической стоматологии, \\ Кыргызская Государственная медииинская академия им. И. К. Ахунбаева; \\ ${ }^{2}$ Даутова Амина Ильдаровна / Dautova Amina - ординатор, \\ специальность: стоматология; \\ 3Жекишева Сагын Жекишевна / Zhekisheva Sagyn - доктор технических наук, профессор, \\ кафедра архитектуры промышленных и гражданских зданий Кыргызской Республики, \\ Кыргызско-Российский Славянский университет им. Б. Н. Ельцина, г. Бишкек, Кыргызская Республика
}

\begin{abstract}
Аннотация: анализ результатов, полученных при изучении вещественного состава представленного фарфорового камня месторождения «Джаны-Джол» показал, что использовать их в природном состоянии в качестве сырья в стоматологии невозможно. В природе естественный природный фарфоровый камень, хотя и несет в себе основные требуемые элементы, но помимо их в нем находятся другие, порой вредные компоненты. Нами изучен вещественный состав представленного фарфорового камня, с помощью химического и минералогического анализов.

Abstract: the analysis of the results received when studying material structure of the presented porcelain stone of the "Dzhany-Dzhol» field has shown that it is impossible to use them in a natural state as raw materials in stomatology. In the nature the natural porcelain stone, though bears in itself the basic required elements, but besides them in it there are others, and at times and harmful components. We have studied material structure of the presented porcelain stone, by means of chemical and mineralogical analyses.
\end{abstract}

Ключевые слова: ортопедическая стоматология, химический анализ, обогащение, керамический продукт, минералогия, фарфоровый камень.

Keywords: orthopedic stomatology, chemical analysis, enrichment, ceramic product, mineralogy, porcelain stone.

Фарфор - керамический продукт, получаемый в результате обжига фарфоровой массы, приготовленной из основных компонентов - полевого шпата, кварца, каолина и красителей.

По химическому составу стоматологические фарфоровые массы стоят между твердым фарфором и обычным стеклом [1]. По своему назначению фарфоровые массы являются исходным материалом для:

- заводского изготовления стандартных искусственных зубов;

- заводского изготовления стандартных фарфоровых коронок и заготовок для фарфоровых вкладок;

- индивидуального изготовления фарфоровых коронок в условиях зуботехнической лаборатории;

- индивидуального изготовления вкладок в условиях зуботехнической лаборатории;

- облицовки цельнолитых каркасов металлических несъемных зубных протезов (коронок, мостовидных протезов).

Целью исследований явилось изучение возможности использования отечественного природного фарфорового камня месторождения «Джаны-Джол» (Учкурт), путем повышения степени очистки, для получения высококачественного материала, который будет применен в ортопедической стоматологии.

Материалы и методы исследования: В процессе исследования природного фарфорового камня было проведено изучение вещественного состава, распределения лимитированных примесей по минеральным составляющим. При этом полученные данные в совокупности, с минералогическими данными, позволяют выбрать необходимые методы очищения и обогащения, а также определить предел обогатимости исследуемого материала, учитывая содержание вредных примесей в обогащенном фарфоровом материале.

Технологические исследования с изучением вещественного состава пробы и проведение необходимых химических анализов на исходном продукте и других продуктах после обогащения, проведены в ГП Центральной лаборатории Государственного агентства по геологии и минеральным ресурсам при Правительстве Кыргызской Республики. Лаборатория аккредитована в соответствии с международным стандартом ИСО/МЭК 17025:2005 (ГОСТ ИСО/МЭК 17025:2009).

1. Изучение вещественного состава пробы

1.1. Химический состав пробы 
В природе естественный фарфоровый камень, хотя и несет в себе основные требуемые элементы, но помимо их в нем находятся другие, а порой и вредные компоненты [2]. Нами изучен вещественный состав представленного фарфорового камня, с помощью химического и минералогического анализов.

Проведенный химический анализ на природный фарфоровый камень представлен в таблице 1.1.

Таблииа 1.1. Результаты химического анализа

\begin{tabular}{|l|c|}
\hline \multicolumn{1}{|c|}{ Наименование элементов и соединений } & Содержание, \% \\
\hline Оксид кремния & 82,67 \\
\hline Оксид алюминия & 0,86 \\
\hline Оксид железа (общ.) & 0,63 \\
\hline Оксид титана & 0,62 \\
\hline Оксид кальция & 0,4 \\
\hline Оксид магния & 0,5 \\
\hline Оксид марганца & - \\
\hline Оксид натрия & 0,5 \\
\hline Оксид калия & 3,08 \\
\hline Оксид фосфора & 0,03 \\
\hline Оксид серы & 0,2 \\
\hline Бор (количественный атомно-эммисионный анализ) & 0,0049 \\
\hline Потери при прокаливании & 1,54 \\
\hline
\end{tabular}

Минералогическим и химическим анализами в природных фарфоровых камнях месторождения Джаны-Джольского установлено повышенное содержание основных лимитируемых примесей - оксидов железа (0,63\%), оксида серы $(0,23 \%)$.

Высокое содержание оксидов щелочных металлов (3,58\%), при преобладании оксида калия $(3,05 \%)$ над оксидом натрия $(0,5 \%)$, обусловлено присутствием в природном фарфоровом камне серицита, альбита и мусковита (минералогический анализ).

Данные факторы предопределяют применение предварительного обогащения для природного фарфорового камня с целью получения продукта, пригодного для использования в стоматологии. Продукт такого качества может быть получен после обогащения механическими методами, включая химическое выщелачивание тонкоизмельченного материала.

В данном случае, пределом обогатимости по железу можно считать содержание оксида железа в твердом остатке после кислотного выщелачивания, т.е. после удаления пленок и вростков железосодержащих минералов.

1.2. Минералогическая характеристика пробы. Минералогическое изучение пробы проводилось по характерным образцам, прозрачным шлифам и продуктам обогащения. Минеральный состав природного фарфорового камня приведен в таблице 1.2 .

Таблииа 1.2. Минеральный полуколичественный состав пробы

\begin{tabular}{|l|c|c|c|}
\hline \multirow{2}{*}{ Наименование минералов } & Содержание & \multicolumn{2}{|c|}{ Размер зерен и агрегатов, мм } \\
\cline { 3 - 4 } & минералов, \% & от & \multicolumn{2}{c|}{ до } \\
\hline Кварц & 83,3 & $<0,01$ & 0,75 \\
\hline Глинисто-слюдистые агрегаты & 10,9 & $<0,01$ & 0,1 \\
\hline Карбонаты (кальцит) & единичные знаки & $<0,01$ & 0,3 \\
\hline Мусковит (серицит) & 0,2 & $<0,01$ & 0,2 \\
\hline Хлорит & единичные знаки & $<0,01$ & 0,25 \\
\hline Турмалин & 0,01 & 0,02 & 0,2 \\
\hline Циркон & 0,01 & 0,02 & 0,15 \\
\hline Анатаз, лейкоксен & 0,02 & 0,01 & 0,1 \\
\hline Рутил & единичные знаки & 0,01 & 0,03 \\
\hline Апатит & единичные знаки & 0,01 & 0,1 \\
\hline Магнетит, мартит & единичные знаки & 0,05 & 1,0 \\
\hline Гидроокислы железа, гематит & 0,8 & $<0,01$ & \\
\hline
\end{tabular}

Анализ результатов, полученных при минералогическом изучении представленного фарфорового камня месторождения «Джаны-Джол», показал, что использовать их в природном состоянии в качестве сырья, пригодного в стоматологии, невозможно. Для этого требуется провести ряд технологических 
операций с целью улучшения их качества: повысить содержание оксида кремния и снизить содержание вредных примесей. Исследования по удалению лимитированных примесей проводились с применением операций механической оттирки, магнитной и электромагнитной сепараций и гравитации. Более глубокая очистка фарфорового камня от железа проводилась химическим выщелачиванием.

1.3. Изучение распределения железа по минеральным составляющим (рациональный анализ железа)

В процессе исследований представленного фарфорового камня месторождения «Джаны-Джол» было проведено изучение распределения железа по минеральным составляющим.

При этом полученные данные в совокупности с ранее приведенными характеристиками позволяют выбрать необходимые методы обогащения и определить теоретический предел обогатимости природного фарфорового камня по содержанию оксида железа в обогащенном фарфоровом камне.

Предел обогатимости по содержанию железа - это то количество железа, которое находится в виде изоморфной примеси в кристаллической решетке зерен кварца.

Рациональный анализ выполнен на материале, крупностью 1,0 мм. Полученные результаты рационального анализа железа приведены в таблице 1.3.

Таблица 1.3. Результаты раџионального анализа железа

\begin{tabular}{|l|c|c|}
\hline Формы нахождения оксида железа & \multicolumn{2}{|c|}{ Оксид железа, \% } \\
\cline { 2 - 3 } & Содержание & Распределение \\
\hline В виде свободных железосодержащих минералов & 0,03 & 3,8 \\
\hline В виде гидроокислов железа & 0,05 & 7,6 \\
\hline В виде вростков рудных минералов и в кальците & 0,10 & 15,4 \\
\hline В виде включений железосодержащих минералов в кварце & 0,10 & 19,3 \\
\hline $\begin{array}{l}\text { В виде изоморфной примеси железа в кристаллической решетке } \\
\text { кварца }\end{array}$ & 0,13 & 38,5 \\
\hline В шламах (класс менее 0,1 мм) & 0,25 & 100 \\
\hline В исходном материале & 0,66 & \\
\hline
\end{tabular}

Анализ приведенных данных (таблица 1,3) показывает, что при крупности материала $-1,0$ мм в пробе $38,5 \%$ оксида железа связано со шламами (-0,1 мм). Это железо можно удалить отмывкой, причем, совместно с глинисто-слюдистыми частицами.

Оксидов железа, находящихся в виде свободных железосодержащих минералов, в пробе до 11,4\%. Для удаления свободных зерен железосодержащих минералов могут быть применены магнитная и электромагнитная сепарации.

Для удаления пленочных примазок и тонких включений железа в кальците, кварце (доля которых в пробе 50,1\%), применимы механическая оттирка и химическое выщелачивание.

\section{2. Технологические испытания.}

\section{1. Методика, направление исследований}

Исследования по удалению лимитированных примесей проводились с применением операций механической оттирки, магнитной и электромагнитной сепараций и гравитации. Более глубокая очистка кварцитов от железа проводилась химическим выщелачиванием.

Эксперименты по технологическому тестированию проводились на представительных навесках крупностью материала - 1,0 мм. Механическая оттирка проводилась в лабораторной флотомашине марки ФМ-1. Для тестов с применением гравитации использовался концентрационный стол СКО-0,5Л. Магнитная сепарация выполнялась ручным магнитом марки РЧ, электромагнитная сепарация - на универсальном электромагнитном сепараторе УЭМ-1. Выщелачивание железа проводилось в емкостях из термостойкого стекла при постоянной агитации.

\section{2. Механическая оттирка и отделение шламистой части}

Истирание проб и продуктов обогащения для аналитических работ проводилось в механической агатовой ступке или вручную - в фарфоровой ступке. Механическая оттирка исходного материала, крупностью 1,0 мм, проводилась во флотомашине в водной среде при отношении Ж: Т = 3:1, с последующей мокрой классификацией по классу 0,1 мм. Время проведения механической оттирки составило 30 минут.

При этом преследовались следующие цели - разрыхление (дезинтеграция) глинисто-слюдистого материала и механическая оттирка пленок гидроокислов железа за счет абразивного воздействия при перетирании зерен друг о друга в процессе перемешивания.

Результаты обогащения оценивались по выходам и результатам анализов продуктов обогащения. 
Последующая классификация позволяет перевести в шламистую часть вредные глинистые минералы и железосодержащие тонкие выделения минералов (рис. 1.1).

Схема обогащения фарфорового камня с применением механической оттирки

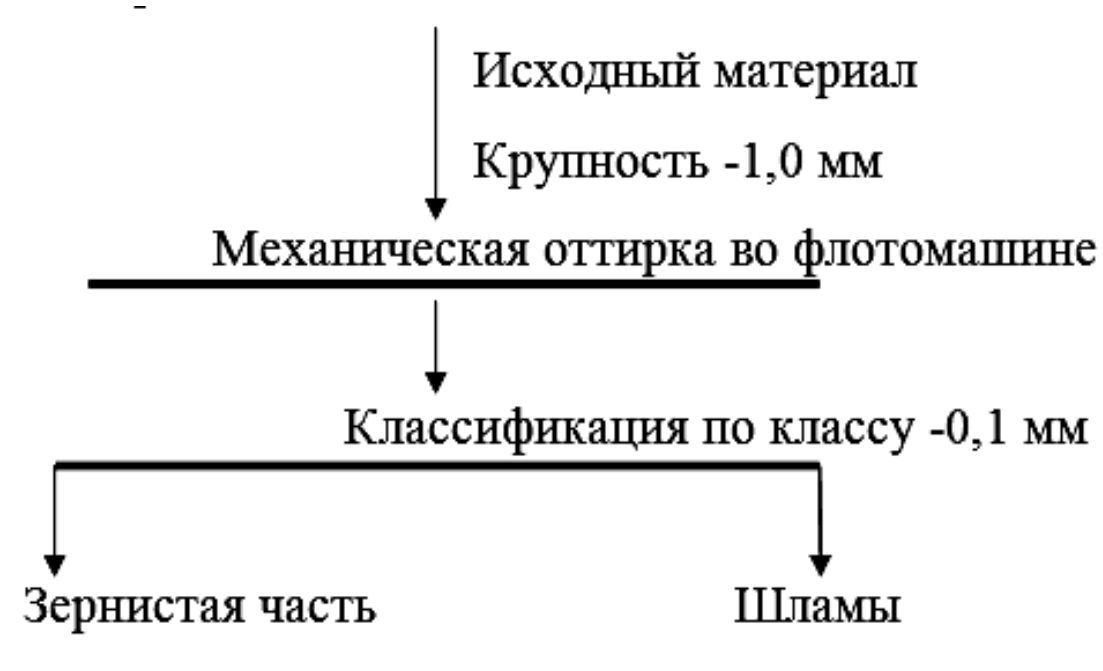

\section{(обогащенный продукт)}

Рис. 1.1. Схема обогащения фарфорового камня с применением механической оттирки

2.3. Обогащение фарфорового камня по схеме «механическая оттирка - магнитная сепарация электромагнитная сепарация»

В составе природного фарфорового камня находятся минералы-носители железосодержащих вредных примесей (гематит, лимонит, турмалин и др.) обладают положительными значениями удельной магнитной восприимчивостью в отличие от фарфора, обладающего диамагнитными свойствами. Этот фактор обусловил возможность применения магнитной и электромагнитной сепараций для дальнейшей очистки полученного зернистого обогащенного продукта от железосодержащих минералов.

Электромагнитная сепарация проводилась при максимально возможной напряженности магнитного поля в 7000 эрстэд. Схема проведения опытов показана на рисунке 1.2 .

Обогащение по схеме «механическая оттирка - магнитная и электромагнитная сепарации» 


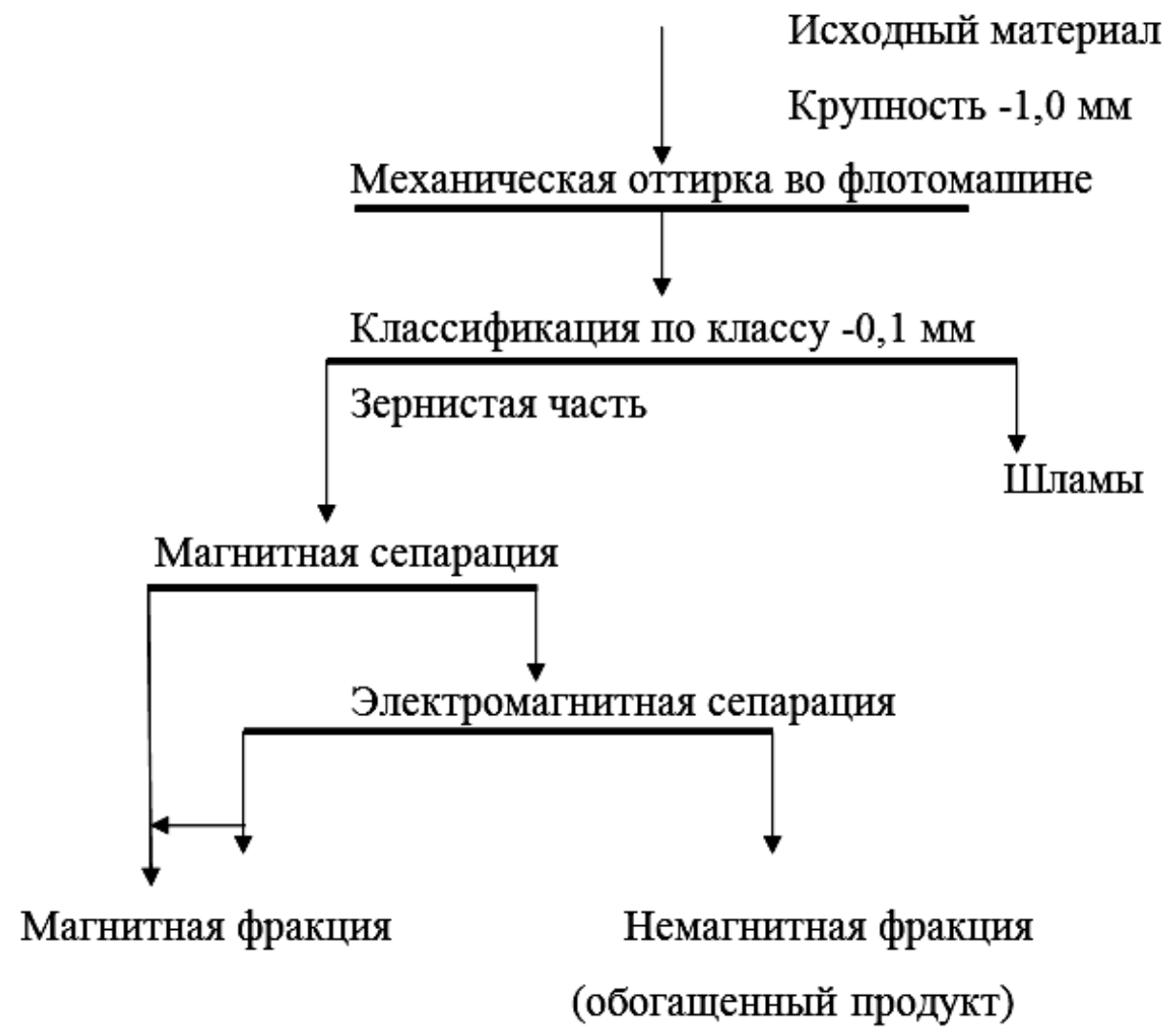

Рис. 1.2. Схема проведения опьтов

2.4. Применение химического выщелачивания для обезжелезнения материала

Для наиболее полного удаления образований с внешней поверхности зерен фарфора и частично из микротрещин была испытана химическая доводка.

Для химической очистки применяют горячие растворы серной, соляной, щавелевой и фтористоводородной кислот. Нами были опробованы растворы щавелевой и соляной кислот. Условия выщелачивание приводятся на рисунке 1.3, результаты тестирования - в таблицах 1.4 и 1.5.

Принципиальная схема обогащения природного фарфорового камня по технологии «механическая оттирка - магнитная и электромагнитная сепарации - солянокислотное выщелачивание» 


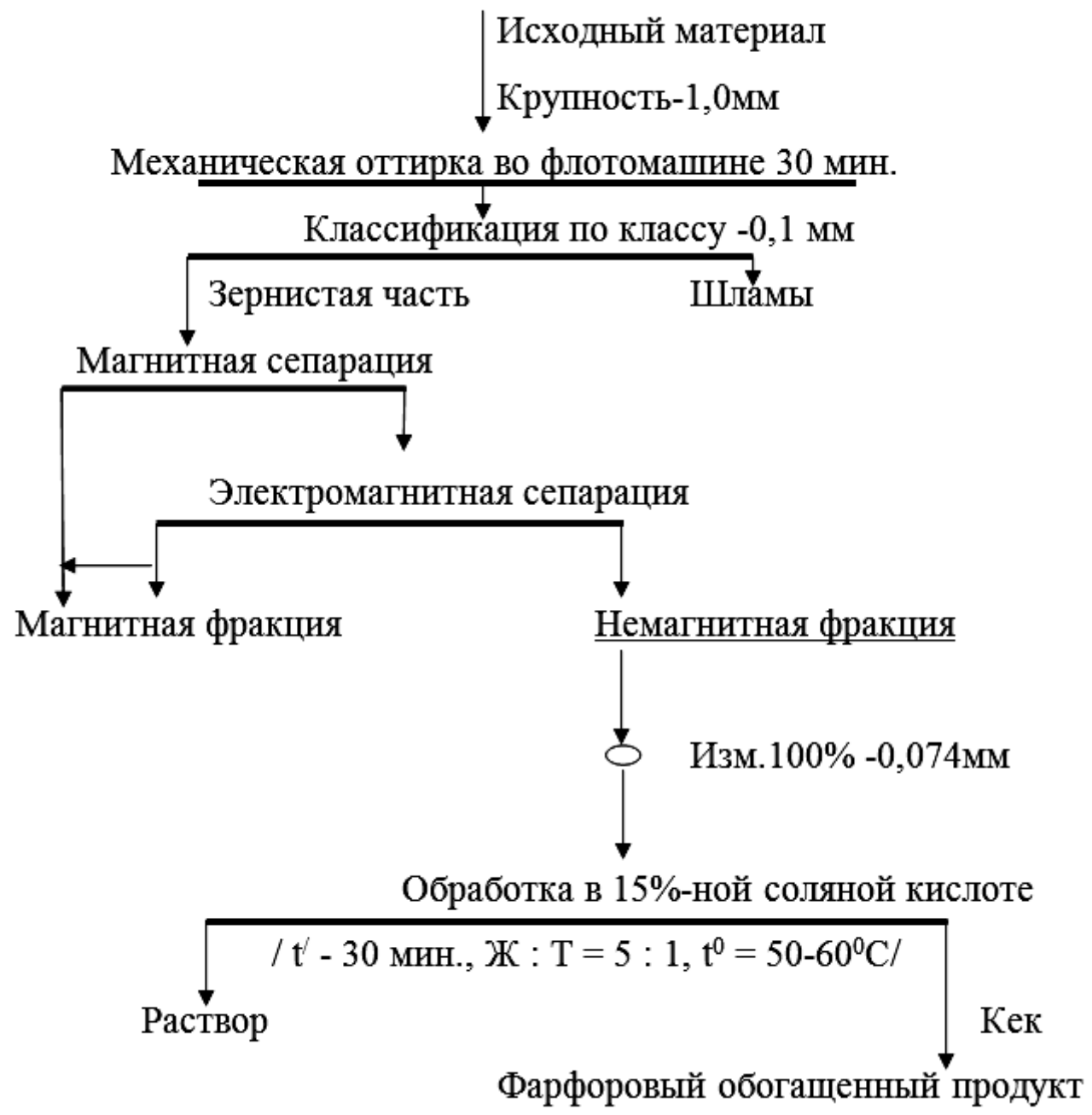

Рис. 1.3. Условия выщелачивания

Таблица 1.4. Условия выщелачивания измельченного фарфорового продукта

\begin{tabular}{|l|c|c|}
\hline \multicolumn{1}{|c|}{ Наименование параметра } & Единица измерения & Величина параметра \\
\hline Продолжительность процесса выщелачивания & минут & 30 \\
\hline Температура пульпы & Градус $\left({ }^{0} \mathrm{C}\right)$ & $60-65$ \\
\hline Отношение жидкого к твердому & Ж: Т & $5: 1$ \\
\hline Концентрация щавелевой кислоты & $\%$ & 15,0 \\
\hline Концентрация соляной кислоты & $\%$ & 15,0 \\
\hline
\end{tabular}

Таблица 1.5. Результаты доводки фарфорового камня с применением химического выщелачивания

\begin{tabular}{|c|c|c|c|c|c|c|c|}
\hline \multirow[b]{2}{*}{ Наименование продуктов } & \multirow{2}{*}{$\begin{array}{l}\text { Выход } \\
\%\end{array}$} & \multicolumn{2}{|c|}{ Оксид кремния $\left(\mathrm{SiO}_{2}\right), \%$} & \multicolumn{4}{|c|}{ Содержание, \% } \\
\hline & & Содержание & $\begin{array}{c}\text { Распределе- } \\
\text { ние }\end{array}$ & $\begin{array}{c}\mathrm{Fe}_{2} \mathrm{O}_{3} \\
+\mathrm{FeO} \\
\end{array}$ & $\mathrm{Al}_{2} \mathrm{O}_{3}$ & $\mathrm{CaO}$ & $\mathrm{P}_{2} \mathrm{O}_{5} ; \mathrm{B}$ \\
\hline $\begin{array}{l}\text { Не обработанный продукт } \\
\text { (исходный) }\end{array}$ & 100 & 82,67 & 100,0 & $\begin{array}{c}0,01+0,6 \\
3 \\
\end{array}$ & 10,86 & 0,4 & 0,03 \\
\hline $\begin{array}{c}\text { Концентрат после } \\
\text { обработки 5\% щавелевой } \\
\text { кис. } \\
\text { от операции } \\
\end{array}$ & 77,8 & 99,4 & 93,6 & $\mathrm{H} / \mathrm{o}$ & $<0,1$ & $\begin{array}{c}\text { Не } \\
\text { обнару- } \\
\text { жен }\end{array}$ & $\begin{array}{c}\text { Не } \\
\text { обнару- } \\
\text { жены }\end{array}$ \\
\hline $\begin{array}{c}\text { Концентрат после } \\
\text { обработки } 15 \% \text { соляной } \\
\text { кис. От операции }\end{array}$ & 78,4 & 99,7 & 94,6 & $\mathrm{H} / \mathrm{o}$ & $<0,1$ & $\begin{array}{c}\text { Не } \\
\text { обнару- } \\
\text { жен }\end{array}$ & $\begin{array}{c}\text { He } \\
\text { обнару- } \\
\text { жены }\end{array}$ \\
\hline
\end{tabular}

В таблице 1.6 приведены результаты полного химического анализа, на продуктах после кислотного выщелачивания. 
Таблииа 1.6. Результаты химического анализа проб после кислотного выщелачивания

\begin{tabular}{|c|c|c|}
\hline \multirow{2}{*}{ Наименование элементов и соединений } & \multicolumn{2}{|c|}{ Содержание после обработки, \% } \\
\hline & Щавелевой кислотой & Соляной кислотой \\
\hline Оксид кремния & 99,4 & 96,1 \\
\hline Оксид алюминия & $<0,1$ & $<0,1$ \\
\hline Оксид железа (III) & $\mathrm{H} / \mathrm{O}$ & $\mathrm{H} / \mathrm{O}$ \\
\hline Оксид железа (II) & $\mathrm{H} / \mathrm{O}$ & $\mathrm{H} / \mathrm{O}$ \\
\hline Оксид титана & $\mathrm{H} / \mathrm{O}$ & $\mathrm{H} / \mathrm{O}$ \\
\hline Оксид кальция & $\mathrm{H} / \mathrm{O}$ & $\mathrm{H} / \mathrm{O}$ \\
\hline Оксид магния & $\mathrm{H} / \mathrm{O}$ & $\mathrm{H} / \mathrm{o}$ \\
\hline Оксид марганца & $\mathrm{H} / \mathrm{o}$ & $\mathrm{H} / \mathrm{o}$ \\
\hline Оксид натрия & $\mathrm{H} / \mathrm{O}$ & $\mathrm{H} / \mathrm{O}$ \\
\hline Оксид калия & $\mathrm{H} / \mathrm{O}$ & $\mathrm{H} / \mathrm{o}$ \\
\hline Оксид фосфора & $\mathrm{H} / \mathrm{o}$ & $\mathrm{H} / \mathrm{o}$ \\
\hline Потери при прокаливании & 0,0 & 0,0 \\
\hline Сера общая & $\mathrm{H} / \mathrm{O}$ & $\mathrm{H} / \mathrm{O}$ \\
\hline
\end{tabular}

Результаты исследований.

Проведены технологические испытания одной пробы природного фарфорового камня месторождения «Джаны-Джол».

Макроскопически - это порода белого цвета с легким сероватым оттенком сланцеватой текстуры, состоящая из кварца - 80-85\%, мусковита, серицита-15-20\%, акцессорных минералов (циркон, сфен, рутил, флюорит, гематит, апатит) до 1\% [3].

Материал пробы представлен кварцем. Макроскопически - это плотные средне-мелкозернистые породы белого, светло-серого, бурого цвета. Текстура пород массивная, структура - гранобластовая [4]. Акцессорные минералы представлены в основном цирконом, турмалином, анатазом, лейкоксеном, рутилом, апатитом, магнетитом, гематитом. Отмечаются единичные зерна пирита и малахита. Представленные фарфоровые камни могут быть отнесены к мусковит-(серицит)-кварцевому биминеральному типу.

Особенность этой породы - обильная вкрапленность рудного материала и акцессориев. Представленные фарфоровые камни могут быть отнесены к мусковит-(серицит)-кварцевому биминеральному типу [5].

Минералогическим и химическим анализами в природных фарфоровых камнях месторождения Джаны-Джольского установлено повышенное содержание основных лимитируемых примесей - оксидов железа, оксида серы. Высокие содержания оксидов щелочных металлов, при преобладании оксида калия над оксидом натрия, обусловлено присутствием в природном фарфоровом камне серицита, альбита и мусковита (минералогический анализ).

В процессе технологических исследований, целью которых являлось получение товарного фарфорового продукта, испытаны методы мокрой классификации природного фарфорового камня при крупности дробления - 1,0 мм, механической оттирки, магнитной и электромагнитной сепарации, химического выщелачивания, а также сочетания этих методов.

Установлено:

1) мокрой классификацией дробленого материала (- 1,0 мм) может быть получен готовый товарный продукт, по содержанию оксида кремния 98,56\%, соответствующий техническим требованиям (приложение 1).

2) по содержанию лимитируемых примесей (оксидов железа - 0,32\%, алюминия - 0,92\%, магния, кальция, фосфора, свинца и бора) фракция крупности - 1,0 мм отвечает техническим условиям, предъявляемым к сырью для стоматологии.

3) основные испытания проведены на материале, крупностью - 1,0 мм. Обязательной операцией в голове схемы является механическая оттирка мелкодробленого (до - 1,0 мм) фарфорового продукта с последующим отделением от зернистой части глинисто-слюдисто-шламистого продукта, содержащегося в дробленом исходном материале. При этом удаляется значительная часть лимитируемых соединений, а содержание кремнезема повышается до 98,75\% против 83,3\% в исходном сырье.

4) дальнейшее повышение обогащенных фарфорового продукта зависит в основном от содержаний примесей в них. С целью последующего обезжелезнения фарфорового продукта опробован ряд технологий, включающих сочетание механической оттирки с другими методами обогащения.

Наиболее эффективна технология обогащения природного фарфорового продукта включает в себя дробление природного материала до крупности - 1,0 мм, механическую оттирку, дешламацию по классу - 
0,1мм, магнитную и электромагнитную сепарации зерновой части, и химическое выщелачивание немагнитной фракции, измельченной в фарфоровой ступке до 100\% - 0,074 мм, горячим 15\%-ным раствором соляной кислоты (рисунок 1.3). Полученный при этом фарфоровый продукт содержит 99,4\% оксида кремния, 0,01\%, оксида алюминия $<0,1 \%$. Оксиды железа, кальция, фосфора и бор или минералы их содержащие, спектральным и минералогическим анализом не обнаружены.

Полученный при этом концентрат пригоден для зуботехнического материала, применяемый для изготовления искусственных зубов. По вещественному составу и технологическим свойствам природный фарфоровый камень месторождения «Джаны-Джол» является перспективным сырьем для получения высококачественного природного концентрата, пригодного в стоматологии.

\section{Лumepamypa}

1. Еремин Н. И. Неметаллические полезные ископаемые. М.: Издательство Московского университета, 2007. $467 \mathrm{c}$.

2. Лыгина T. 3. Методические основы комплексной оценки состава и свойств неметаллических полезных ископаемых.: Автореф. дис. ... докт.техн.наук. Москва, 2001. 50 с.

3. Масленникова Г. Н., Жекишева С. Ж., Кудряшов Н. И. Керамическое сырье Центральной Азии. Б.: изд-во «Технология», 2002. $231 \mathrm{c}$.

4. Михеев В. Г. Неметаллические полезные ископаемые (учебное пособие). Красноярск, 2003. 159 с.

5. Жекишева С. Ж., Амираев У. А., Даутова А. И., Глубоков В. А. Петрогенетика фарфорового камня месторождения Джаны-Джол (Учкурт) Кыргызской Республики // Проблемы современной науки и образования. Иваново, 2016. № 8 (50). С. 157-161. 